\title{
POLÍTICAS PÚBLICAS PARA A AGRICULTURA FAMILIAR: o PAA e o PNPB
}

\author{
Public Policy for Agriculture Family: the PAA and PNPB \\ Dinalva Donizete Ribeiro * \\ Mariza Souza Dias **
}

\begin{abstract}
Resumo
As políticas públicas para a Agricultura Familiar, enquanto estratégia para o desenvolvimento do capitalismo no campo brasileiro, promovem tensões e conflitos para as famílias que as utilizam. Pautam-se em programas, aç̃es e estratégias com o intuito de inserir as famílias nas cadeias produtivas, tornando-as adequadas ao sistema de mercado. Ao mesmo tempo em que essas políticas públicas negam a racionalidade camponesa, ocultam questões estruturais do campo, como a necessidade da reforma agrária, a exploração e expropriação da renda e os conflitos (re)existentes. Para tratar e analisar tais questões, com destaque para os conflitos que permeiam a relação entre políticas públicas e famílias camponesas, foram analisados os processos de implantação do Programa de Aquisição de Alimentos da Agricultura Familiar (PAA) e do Programa Nacional de Produção e Uso do Biodiesel (PNPB) em assentamentos rurais nos municípios de Jataí e Perolândia, na microrregião Sudoeste de Goiás. Os dados apresentados e discutidos compõem uma pesquisa vinculada ao Programa de Pós-Graduação em Geografia da Universidade Federal de Goiás, Campus Jataí, desde 2010.
\end{abstract}

Palavras-chave: Políticas Públicas, Assentamentos Rurais, Campesinato, Agricultura Familiar.

\begin{abstract}
The public policy for Family Agriculture, as a strategy of capitalist development in Brazilian countryside promotes tensions and conflicts to the families that make use of them. This policy is based on programs, actions and strategies that aim to insert the families in the production process, making them suitable to the market system. At the same time it denies the peasant rationality, it hides structural issues of the field, such as the need for land reform, exploitation and expropriation of the wealth and conflicts (re)existents. In order to handle and analyze such issues, highlighting the conflicts surrounding the relation between public policy and peasant families, it was analyzed the processes of implementation of the Production and Use of Biodiesel National Program (PNPB) and the Acquisition of Food from Familiar Agriculture Program (PAA), in rural settlements in Jataí and Perolândia, in the Southwest area of Goiás. The data presented and discussed make up a larger research bounded to the Graduation Program in Geography from Goiás Federal University, Campus Jataí, since 2010.
\end{abstract}

Key words: Public Policy, Rural Settlements, Peasant, Familiar Agriculture.

\section{Résumé}

La politique publique pour l'Agriculture Familiale en tant que stratégie du développement du capitalisme, dans la campagne brésilienne amène à des tensions et des conflits les familles bénéficiaires. Cette politique est basée dans des programmes, actions et stratégies avec le but d'insérer les familles dans le processus productif, devenant ainsi mieux adaptées au système du marché. En même temps qu'elle nie la rationalité paysanne, elle cache des questions structurelles de la campagne, comme le besoin de reforme agraire, l'exploration, l'expropriation de la rente et les conflits (à nouveau) existants. Pour traiter et analyser ces questions, mettant en valeur les conflits qui se tissent dans la relation entre politiques publiques et familles paysannes, furent analysés les processus d'implantation du Programme National de Production et Utilisation de Biocarburant (PNPB) et le Programme d'Acquisition d'Aliments de l'Agriculture Familiale (PAA), dans des établissements ruraux de la réforme agraire dans les villes de Jataí et Perolândia, dans la microrégion du sud-ouest de Goiás. Les données présentées et discutées composent une recherche plus grande, liée au programme de Post-graduation en Géographie de l’Université Fédérale de Goiás depuis 2010.

Mots-clés: Politique Publique, Réforme Agraire, Agriculture Paysanne, Agriculture Familiale

(*) Prof ${ }^{\mathrm{a}}$. Dra . da Universidade Federal de Goiás - Campus Samambaia. Rodovia Goiânia / Nova Veneza, Km 0, Caixa Postal 131, CEP 74.690-900, Goiânia (GO), Brasil. Tel.: (+55 62) 3521-1556 - dinalvadr@gmail.com

(**) Msc. pela Universidade Federal de Goiás - Campus Jataí. BR 364, Campus Jatobé, BL 5, Sala NEAF, CEP: $75800-000$ Jatai (GO), Brasil. Tel: (+ 55 64) 36068255 - mariza_dias@yahoo.com.br 


\section{INTRODUÇÃO}

As políticas públicas brasileiras para a Agricultura Familiar, instituídas a partir da década de 1990, se pautam na reprodução do processo histórico de desenvolvimento econômico do Brasil. Isto significa que tais políticas preconizam as formas de acesso à renda e as oportunidades de crescimento pelo viés da reprodução do capital, uma vez que não são modificadas as suas estruturas de exploração (FERNANDES, 2008).

Já foram implantados vários programas que visam a inserção dos agricultores familiares no mercado. O Programa Nacional de Fortalecimento da Agricultura Familiar, o PRONAF, criado em 1995 e a Lei da Agricultura Familiar, Lei no 11.326, de 24 de julho de 2006, institucionalizaram como agricultura familiar todas as pequenas formas de exploração econômica nos campos, nas águas e nas matas brasileiras, incluindo as microempresariais. No entanto, estudiosos como Oliveira (2007), Fernandes (2008) e Paulino (2010), dentre outros, demonstram que o campesinato é plural tanto em formas produtivas como em territórios ocupados.

Da mesma forma que essa unificação proporciona uma representação política mais abrangente para estes sujeitos, também oculta conflitos que ocorrem entre eles e outros atores sociais - Estado, sociedade, mercado.

Programas oriundos desta política, como o Programa de Garantia de Preço à Agricultura Familiar (PGPAF), o Seguro Safra, PNPB, Mais Alimentos, dentre outros, beneficiam mais o mercado e o sistema financeiro do que os agricultores, propriamente. O discurso do Estado, de melhoria da produção e da renda das famílias agricultoras, esconde intenções políticas, como a negação da reforma agrária.

Os governos, emparelhados com o capital, se abstêm da redistribuição de terras, da reforma agrária e da estruturação, nas zonas rurais, de serviços públicos de saúde, educação e lazer. Assim, o país legitima as leis de mercado metamorfoseando famílias camponesas em agricultores familiares. Os programas seriam os casulos, as pupas. Por meio deles as famílias fariam parte do mercado como fornecedoras competitivas.

Essa é uma estratégia do processo de exploração capitalista das terras e da apropriação da sua renda. Apenas reconhece as famílias camponesas como potenciais sujeitos econômicos, desde que guiados por programas de governo ou pelo mercado. A finalidade da permanência deles na terra é meramente econômica.

O fato das famílias camponesas possuírem os meios de produção (terra e ferramentas) e o trabalho (mão-de-obra) dá-lhes um padrão singular de autonomia. Elas conseguem controlar a maior parte das etapas produtivas e desvencilhar sua renda da expropriação capitalista, sem, contudo, negarem o mercado. Pelo contrário, aproveitam as oportunidades, para obterem renda, sem que isso signifique, necessariamente, cooptação.

A forma como as políticas públicas para a agricultura familiar vêm sendo propostas impele as famílias a participarem de programas como se essa fosse a saída, única, para sua sobrevivência. No entanto, essas políticas comprimem as formas e o tempo da produção camponesa, porque ela passa a ter que se adequar às normas do mercado e efetivam o controle do seu território, como têm debatido diversos pesquisadores, principalmente os que tratam a resistência camponesa no campo monopolizado pelo capitalismo como cerne da questão agrária.

Quando os programas são incorporados pelas famílias agricultoras, principalmente as assentadas, a reprodução econômica e social fica subordinada a eles, o que é, talvez, a pior ameaça ao campesinato. São muitos os conflitos e tensões resultantes dessa situação.

Buscar-se-á demonstrar neste artigo como e quais conflitos emergem da implantação do Programa Nacional de Aquisição de Alimentos da Agricultura Familiar (PAA) e do Programa Nacional de Produção e Uso do Biodiesel (PNPB) e da adesão a eles de famílias assentadas nos municípios de Jataí e Perolândia, na microrregião Sudoeste de Goiás, levando-se em consideração as intenções 
e a racionalidade camponesa, que questionam e reorganizam as estratégias produtivas implícitas e impostas por estes programas.

\section{CONTEXTUALIZANDO AS POLÍTICAS PÚBLICAS PARA A AGRICULTURA FAMILIAR}

Conforme Paulino (2010) é preciso refletir, no âmbito da produção científica, sobre as bases teóricas e ideológicas das políticas públicas enquanto instrumentos de intervenção nos territórios, a serviço do capital, principalmente no caso dos assentamentos, que são espaços reterritorializados pelas famílias camponesas.

Implantado no Brasil, a partir da década de 1990, o conceito de Agricultura Familiar é norteado pelo paradigma do capitalismo agrário, que toma a Agricultura Familiar como mais uma unidade do sistema capitalista e pela ideia de que o camponês só estará bem se integrado ao capital (FERNANDES, 2008).

Dessa forma, foram criados programas e ações para inserir as famílias camponesas no mercado produtivo, com o objetivo de suprimir o suposto caráter parcial de sua economia, integrando-as às formas de produção e de trabalho capitalistas considerando apenas o seu potencial econômico. Esta postura político-econômica se baseia no ideário neoliberal em voga naquele momento.

Tal postura foi legitimada pelos estudos de Abramovay (1992), que afirmou que as famílias camponesas necessitam abandonar essa "economia parcial" para adentrar o sistema capitalista, já que este tipo de economia é um entrave ao seu pleno desenvolvimento. Assim, essa economia parcial devia ser transformada e/ou reformulada para que compusesse o capitalismo, no qual as famílias camponesas passam a agricultores familiares.

Foram reformuladas as políticas públicas para o campesinato. Foram tiradas da pauta de discussões temas estruturais, como a reforma agrária, os movimentos sociais, a falta de serviços públicos no campo e, ainda, efetivou-se a criminalização das ocupações de terras.

Toda essa construção teórica serviu para manter a estrutura agrária concentrada, criminalizar as estratégias dos movimentos que buscam a redistribuição das terras e criar programas, quase que exclusivamente, de assistência social e de inserção comercial.

Todas essas ações, do Estado e do capital, geram conflitos, mesmo porque se dão numa sociedade de classes, divergente na sua essência. Há que se analisar com acuidade os conflitos e seus desdobramentos, senão, corre-se o risco de criar a imagem de que o campo é um espaço sem conflitos de classe, o que, em realidade não o é.

Entre outros autores, Fernandes (2008) e Oliveira (2007) discutem esta realidade. Para eles, no entanto, as famílias camponesas, ao se apropriarem das possibilidades produtivas que o capitalismo oferece, estão, também, questionando a dominação deste sistema, porque a terra nunca será apenas condição de produção de mercadorias, mas, da produção da vida, em plenitude, de recriação continuada do campesinato.

Ao se analisar a questão agrária no Brasil é preciso, portanto, colocar as famílias camponesas como sujeito no processo de produção política e econômica do campo, não apenas como reprodutoras do sistema vigente. Pode-se, assim, perceber a luta, a politização, as tensões, as disputas de expressão do campesinato, o qual se apropria, repensa, readequa e, até mesmo, rejeita políticas públicas, que possam comprometer seu modo de vida.

Conforme Mazzeto Silva (2006), para se compreender as políticas públicas para o meio rural no Brasil é preciso considerar o projeto de sociedade que se pretende viabilizar. Quando se quer inserir o campesinato no mercado, que rege a sociedade de consumo, afirma-se a hegemonia do capitalismo. Mas, se os órgãos e os programas criados a partir das políticas públicas para a agricultura familiar gerassem uma série de iniciativas que apoiassem, em âmbito local e regional, a implantação e o desenvolvimento de atividades baseadas em valores, princípios, enfoques, métodos e propostas produtivas próprias do campesinato, tornando-o como sujeito central do processo, estar-se-ia gerando um novo modelo de desenvolvimento social para o Brasil. 
Para Marques (2004), os camponeses disputam o espaço público, politizam a vida cotidiana e intentam aprender as regras do jogo da política, mudam de posição social e buscam caminhos para romper com a condição de subalternos. No centro dessa situação, está uma utopia social que alimenta as resistências e o papel protagonista do campesinato na negação da universalização das relações mercantis, porque quando ele não aceita ser submetido ao mundo do mercado, mostra uma alternativa.

Entretanto, quando as políticas públicas para a agricultura familiar a partir de programas e ações privilegiam diretamente o Estado e o capital, nega-se, destrói-se a possibilidade de as famílias camponesas manterem seu modo de desenvolver atividades econômicas, que é sustentável.

Institucionalmente, a concepção e a condução das políticas públicas para a agricultura familiar é atribuição do Ministério do Desenvolvimento Agrário (MDA), que oficialmente afirma querer promover o desenvolvimento rural sustentável, baseando-se em quatro eixos: combate à pobreza rural, segurança e soberania alimentar, sustentabilidade dos sistemas de produção e geração de renda e agregação de valor (MDA, 2010).

No entanto, conforme Felício (2006), esse modelo de desenvolvimento territorial rural gestado pelo MDA e pela Secretaria da Agricultura Familiar (SAF) tira o foco principal da questão agrária, que é a necessidade da reforma agrária e da desconcentração das terras, transferindo para o capitalismo agrário, para o mercado, a responsabilidade pela transferência de renda e, por consequência, pela diminuição da pobreza rural.

O Estado brasileiro, através do MDA e da SAF, em parceira com outros ministérios, como o Ministério do Desenvolvimento Social e Combate à Fome (MDS), Ministério da Agricultura, Pecuária e Abastecimento (MAPA), Ministério da Ciência e Tecnologia (MCT), implementa políticas públicas apoiado no discurso de inclusão social e econômica e de resgate e valorização da cultura tradicional, com a participação das famílias agricultoras no processo de desenvolvimento social do país (MDA, 2010).

Dentre os programas para agricultura familiar desenvolvidos pelo MDA estão o Programa de Aquisição de Alimentos da Agricultura Familiar (PAA), instituído pela Lei no 10.696, de 2 de julho de 2003, o Programa Nacional de Alimentação Escolar (PNAE), e o Programa Nacional de Produção e Uso do Biodiesel (PNPB) normatizado pela Lei n ${ }^{\circ} 11.097$, de 13 de janeiro de 2005, que conta com a atribuição do Selo Combustível Social (SCS) às empresas que adquirem oleaginosas de agricultores familiares - Decreto $N^{0}$ 5.297, de 6 de dezembro de 2004 (MDA, 2010).

O PAA e o PNPB diferem na sua essência. Enquanto o PAA visa a produção de alimentos, sendo o Estado o próprio comprador, o PNPB visa a produção de energia via oleaginosas, das quais a soja representa mais de $80 \%$, mas, quase que exclusivamente, é o mercado, a empresa compradora e, em alguns casos, a cooperativa, que regula o processo.

No caso do PAA, as famílias camponesas participam e se envolvem efetivamente na sua implantação, seja como produtoras ou como gerenciadoras. Já no PNPB não há envolvimento direto das famílias, que recebem o pacote para o plantio e a venda das oleaginosas produzidas é mediada, necessariamente, por uma empresa e/ou cooperativa.

Ambos os programas preveem a participação das famílias assentadas, exercendo o que acaba se tornando uma forma de controlar o território delas e de criação de um outro modo de vida em cujo cotidiano entram processos burocráticos que não fazem parte do modo de vida camponês. Estabelecem-se, assim, conflitos e tensões, pois são vários os sujeitos que buscam a produção por razões e fins que divergem na essência. Por isso, a análise dos programas, que são a concretização da política pública para a agricultura familiar, deve levar em conta não apenas a produção e a renda, mas outros elementos próprios do modo de vida camponês, das famílias que os implementam.

A compreensão destes Programas deve considerar os outros fatores em jogo, como economia, segurança alimentar, autonomia, adequação ou negação aos programas, uso da terra e do trabalho, controle do tempo e domínio do território. Desse modo, encontrar-se-ão as razões que fazem com 
que famílias se disponham ou não a participar desses programas e poder-se-á melhor avaliá-los. Parte-se do pressuposto de que as respostas estão nas interações.

\section{PAA: UMA PROPOSTA DE ASSISTÊNCIA SOCIAL, QUE CORRE O RISCO DE TORNAR-SE ASSISTENCIALISTA E DE POLÍTICA COMERCIAL}

Conforme o próprio MDS (2010), o PAA é uma política de assistência social aos agricultores familiares, entretanto, é conduzida como uma política comercial. Por meio deste programa adquirem-se os alimentos produzidos pelas famílias camponesas, com isenção de licitação, a preços compatíveis aos praticados nos mercados regionais.

O PAA foi criado no Plano Safra 2003/04 e até então era inédita a presença do Estado na comercialização da pequena produção familiar. No ano de 2009 foram aplicados R\$ 628 milhões no PAA, um aumen $\neg$ to de quase quatro vezes em relação a 2003 (R\$ 164,4 milhões) (GRISA e WESZ JR, 2010).

A pesquisa realizada entre 2010 e 2012 em dois assentamentos no Sudoeste de Goiás constatou que sua operacionalização é afetada por alguns fatores: dificuldades na organização e planejamento da produção agrícola, falta de assessoria técnica, obstáculos no acesso à DAP (Declaração de Aptidão ao PRONAF), atraso na liberação dos recursos e problemas de logística (transporte e armazenamento dos alimentos).

Ademais, o número de famílias be $\neg$ neficiadas ainda é pouco expressivo em nível na $\neg$ cional e a quantidade de recursos alocados é pouco significativa. Também, salienta-se a importância de se ter atenção para que estas famílias não se tornem dependentes deste merca $\neg$ do institucional como a única opção de comercialização de seus produtos (GRISA e WESZ JR, 2010).

Os alimentos produzidos e comercializados por este Programa são destinados à rede sócio-assistencial e às instituições públicas de alimentação e nutrição como: restaurantes populares, cozinhas comunitárias e bancos de alimentos para famílias e grupos em situação de vulnerabilidade social e em risco alimentar.

Estima-se que, em 2008, o PAA atingiu apenas 4\% do público-alvo. Já em 2009, conforme os dados do $3^{\circ}$ Seminário do PAA (2010), apenas 3,29\% dos agricultores familiares brasileiros participaram do Programa. Os recursos aplicados no ano de 2009 foram de R $\$ 591,00$ milhões destinados a 137.185 famílias, que proporcionou uma renda média anual de $\mathrm{R} \$ 4.300,00$ e média mensal de R\$358,00 para cada família.

Na região Centro-Oeste só 2,15\% dos agricultores familiares aderiram ao Programa em 2009 e foram aplicados apenas 2\% dos recursos do PAA nessa região (PAA, 2010). Em Goiás, dos 246 municípios, apenas Jataí participa do PAA, na modalidade municipal, na qual é o município que elabora e gerencia o Programa.

O PAA, em oito anos de existência, só conseguiu atingir, em média, pouco mais de $3 \%$ dos agricultores familiares brasileiros, o que o torna mais simbólico do que efetivo.

Para Duval e Ferrante (2008), o PAA, de modo geral, tem estimulado os pequenos agricultores a permanecerem ou a retornarem ao modo específico de funcionamento do campesinato, principalmente em relação ao sistema de policultivo, tem ajudado a melhorar a qualidade da alimentação para o autoconsumo devido à diversificação da produção. Além disso, as famílias têm se voltado à produção agrícola, deixando de procurar alternativas de trabalho na cidade ou mesmo não-agrícolas no campo.

Porém, o PAA também gera conflitos, principalmente quando impõe excessivas regras e normas burocráticas, o que representa dificuldade para as famílias camponesas e apresenta falhas na logística e nos moldes de funcionamento que fazem com que muitas famílias desistam do Programa.

As famílias tendem a se adequarem melhor e mais rapidamente àquelas regras que convergem com seus interesses, o que demonstra consciência do seu papel político e econômico nos progra- 
mas. Mas, no decorrer do processo, elas também se adaptam às outras normas, pois não há como reorganizar todas as ordens burocráticas nem como escapar facilmente.

O Programa, para as famílias camponesas, tem um papel mais amplo do que apenas inseri-las ou não num mercado mais equitativo; ele passa a fazer parte da reprodução e do cotidiano delas. A partir do momento em que começam a produzir os alimentos para este fim, parte do tempo, do trabalho, dos aprendizados, dos recursos e da terra é consumida pelo Programa. Logo, não é apenas o aumento da renda que está em questão, pois, para se alcançar esse objetivo, corre-se o risco de mudar o modo de vida.

Dessa forma, este tipo de política pública, ao visar ampliar as possibilidades de produção e comercialização, como se as famílias camponesas não possuíssem capacidade de produzir e se manter na terra do seu próprio jeito, pode afetar o modo de vida camponês. Como propõe Paulino (2010), é preciso desconstruir a ideia de que a agricultura de pequena escala é inviável no atual estágio de reprodução das forças produtivas, por ser supostamente incapaz de gerar renda aos que nelas trabalham.

\section{CONFLITOS DO PAA PARA FAMÍLIAS ASSENTADAS}

O município de Jataí-GO desenvolve o PAA na modalidade municipal desde 2008. O Programa é efetivado pela modalidade Compra com Doação Simultânea (CDS), por meio da Secretaria da Assistência Social do município. Os alimentos são adquiridos das famílias e distribuídos a creches, asilos, hospitais, instituições públicas, escolas, abrigos.

As famílias dos assentamentos e das comunidades que aderem ao Programa devem cumprir um cronograma de produção e de entrega, manter a qualidade e apresentar os alimentos no padrão que é exigido pelo mercado, controlar os relatórios de recebimentos, emitir as notas fiscais referentes aos produtos entregues e ter uma conta bancária para receber o pagamento. Mas, a consecução dessas ações é acompanhada de conflitos e de readequações feitas pelas famílias.

As regras impostas aplicam-se principalmente na qualidade e no aspecto dos alimentos, que devem seguir um padrão: estar sadios, limpos, embalados individualmente ou em quilos, descascados (para os produtos em que isso se aplica, como o milho). Todas estas regras devem ser cumpridas, sob pena de devolução do alimento.

Essa adequação e adesão ao mercado, apesar de poder causar problemas para as famílias camponesas, como os devido a trocas econômicas desequilibradas, entre outros, as transforma em atores políticos reconhecidos que professam outros valores e concepções de mundo. Para Neves (1999), a relação com o mercado, longe de ser vista apenas como um aspecto da subordinação dos camponeses ao mercado e uma estratégia de minimização dos seus efeitos perversos, deve ser lida como fator político-econômico importante na afirmação social dos assentados.

Dessa forma, o PAA, que insere a agricultura camponesa no mercado de forma diferente por causa da ação direta do Estado como comprador, também possibilita condições concretas de reprodução física e social do campesinato, especialmente dos assentamentos, além de demarcar o seu reconhecimento político como agente econômico. Por isso, especialmente políticas públicas que incentivam a produção de alimentos são aceitas e requeridas pelas famílias camponesas, mesmo que seu desenvolvimento seja permeado de conflitos.

Participaram do PAA em Jataí, no ano de 2011, cem famílias, das quais vinte e nove são produtoras individuais, sete são da Associação São Domingos e sessenta e quatro são de assentamentos, a saber: treze do Rio Claro, nove do Terra e Liberdade, sete do Guadalupe, nove do Rio Paraíso, onze do Santa Rita, oito do Gurita. Sete são dos assentamentos Três Pontes e Lagoa do Bonfim, localizados no município de Perolândia-GO.

O projeto do PAA que foi implantado para 2011 e 2012 em Jataí fornece uma cota de R\$ 4.500,00 por ano para cada família. O valor total de Programa é de R \$900.000,00. 
Quando do lançamento do Programa no ano de 2011 em Jataí, a Secretaria Municipal de Assistência Social fez ampla propaganda e divulgação, apresentando as famílias camponesas como produtoras de alimentos para o município. Mas, ao mesmo tempo, essa situação atrela a promoção e o desenvolvimento do Programa diretamente ao governo municipal, o que pode significar o seu atrelamento a uma determinada gestão e a um determinado grupo político.

Ter um órgão externo que gerencie o Programa, neste caso a Secretaria Municipal de Assistência Social, desonera as famílias da obrigação de fazer a contabilidade exigida, mas permanecem alguns trâmites burocráticos da gestão e a logística de entrega dos alimentos como dificuldades/ problemas deste Programa, que, em muitos casos, inviabilizam a renovação dos contratos. No município de Perolândia, a Associação do Assentamento Três Pontes deixou de renovar o contrato com o PAA, que havia sido gerenciado por ela no ano de 2009, por causa de dificuldades na gestão, como emissão de notas fiscais e prestação de contas.

As famílias camponesas procuram se adequar às normas, entretanto, encontram dificuldades principalmente por questão de tempo e acesso aos órgãos responsáveis. Por exemplo, muitas ficam sem receber o pagamento porque não conseguem cumprir o prazo para emissão da nota fiscal, que é até o quinto dia útil de cada mês ou não podem ir à cidade na data determinada ou, ainda, porque preferem economizar os recursos gastos com a emissão da nota fiscal.

Mas, talvez, a maior dificuldade encontrada pelas famílias que aderem a Programa é a morosidade. No caso do PAA, em Jataí, para o ano de 2011, as reuniões para definição dos participantes se iniciaram em setembro de 2010 e o Programa só foi efetivado em março do ano seguinte.

Como foi divulgado que as entregas se iniciariam em janeiro, muitas famílias começaram a produzir os alimentos em novembro, para, em janeiro, estarem no ponto ideal de colheita. Entretanto, o tempo gasto para aprovação e implantação do Programa fez com que os recursos fossem liberados apenas em março, quando, então, se iniciaram as entregas. As famílias perderam grande parte da produção e todos os investimentos feitos para adiantar o plantio a fim de ter os produtos em ponto de entrega no início de 2011.

Neste caso, as famílias possuem capacidade de produzir em conformidade com um cronograma, mas, justamente por quererem cumpri-lo, tiveram prejuízos. Em entrevistas, as famílias denunciaram o descomprometimento do poder público com o cumprimento de prazos e com a possibilidade de viabilizar entregas fora do prazo, o que evitaria perda do trabalho, dos alimentos produzidos e dos recursos econômicos e naturais utilizados.

Em programas como o PAA, as consequências da dependência das famílias em relação aos governos podem ser desastrosas. A diminuição ou o fim delas só é possível pelo reconhecimento de que mais do que uma relação econômica, nesse tipo de programa há relações políticas e sociais. No caso estudado, a Prefeitura de Jataí vem cumprindo com as proposições feitas no início do Programa e reconhece as famílias como sujeitos no processo, mas é preciso acompanhar o seu desenrolar, uma vez que as tensões podem ocorrer em qualquer momento do processo.

\section{PNPB: SUAS INTENÇÕES E REVELAÇÕES}

Conforme Flexor (2011), a produção de biodiesel já era possível desde o final do século XIX, mas ele só foi utilizado nas décadas de 1930/40, na Segunda Guerra Mundial e nas grandes crises do petróleo da década de 1970. No Brasil, os investimentos iniciaram-se entre os anos de 1990 e 2000, com o apelo mundial por energias limpas (FLEXOR, 2011).

Em 2002 foi criado o Programa Brasileiro de Biocombustíveis (Probiodiesel), com a participação de um conjunto de organizações e instituições de grande porte, para a produção de biodiesel de soja, o que beneficiava os grandes empresários do ramo, principalmente da região Centro-Oeste (FLEXOR, 2011). 
Entre 2003 e 2005 a política do programa foi reformulada e foi instituído o Programa Nacional de Produção e Uso do Biodiesel (PNPB). A principal modificação foi a entrada dos agricultores familiares, especialmente os do Nordeste, como produtores de oleaginosas. Para estimular a parceria entre os agricultores familiares e as instituições privadas que compram as matérias-primas e industrializam o biodiesel, o Estado fornece subsídios fiscais e melhores preços para as empresas, brindando-as com o Selo Combustível Social (SCS).

Desse modo, no Centro-Oeste, por meio do PNPB, as famílias de assentamentos rurais puderam adentrar legalmente no universo da produção de soja, embora, na maioria dos assentamentos já existisse a prática do arrendamento para a produção de soja, que era e é ilegal, mas é comum.

Conforme o MDA (2010), o PNPB apoia a participação da agricultura familiar na cadeia de produção do biodiesesl de soja com a criação de instrumentos como crédito, zoneamento, assistência técnica e extensão rural, fomento e benefícios fiscais (SCS). As metas do PNPB são: implantar um programa sustentável, promovendo inclusão social, garantir preços competitivos, qualidade e suprimento e produzir o biodiesel a partir de diferentes fontes oleaginosas e em regiões diversas (MDA, 2010).

O principal instrumento do PNPB é o Selo Combustível Social, que é a redução de impostos concedida pelo MDA às empresas que comprarem matéria-prima dos agricultores familiares, $15 \%$ no caso da produção dos empreendimentos do Centro-Oeste (MCT, 2010).

Um outro instrumento, que consta na Lei 11097/05, que estabeleceu o Programa, é a adição obrigatória de 5\% de biodiesel ao diesel fóssil que só se iniciaria em 2013, mas foi antecipada para o ano de 2010 (FLEXOR, 2011).

Diante dessas premissas de inclusão social e comercial foi criada a Comissão Executiva Interministerial, sob o comando do Ministério de Ciências e Tecnologia (MCT), para apoiar os pequenos agricultores e o desenvolvimento científico e tecnológico do biodiesel (MDA, 2010).

A concessão de crédito às famílias que quiserem fazer parte da cadeia de produção do biodiesel é feita através de uma linha de crédito adicional do PRONAF para o cultivo de oleaginosas.

A organização não governamental Repórter Brasil (2010), alerta que este processo precisa ser melhor debatido pela sociedade, pois a maior parte da produção de soja é feita por grandes produtores e ela domina $80 \%$ do mercado nacional de matérias-primas para a produção de biodiesel. Isso, na prática, revela mais do que o fracasso do programa oficial de inclusão de pequenos produtores de mamona e dendê na cadeia dos agrocombustíveis renováveis, indica também que todos os problemas ambientais, sociais e trabalhistas causados pelo atual modelo de produção da sojicultura podem permanecer na produção de biodiesel de soja, o que comprovaria a falsidade dos discursos empresariais e governamentais de que os agrobiocombustíveis brasileiros são paradigma da chamada "energia limpa” (REPÓRTER BRASIL, 2010).

No PNPB, portanto, estão envolvidos, além dos agricultores familiares, agentes e mediadores com vários interesses, como cooperativas, empresas privadas compradoras de grãos e de comércio de insumos e o Estado.

No estado de Goiás, no ano de 2011, cerca de 1.700 agricultores familiares participaram da produção de biodiesel. Mais de 90\% plantam soja. Na microrregião Sudoeste de Goiás, conforme dados da Cooperativa de Agricultores Familiares do Projeto de Assentamento Rio Paraíso (COPARPA), aproximadamente 500 famílias produziram soja destinada para o PNPB na safra 2010/2011. Esta cooperativa faz parceira com três empresas: Caramuru, Grannol e Brasil Ecodiesel, que compram a produção das famílias da região. A implantação do PNPB nos assentamentos rurais pesquisados foi realizada pela Caramuru e pela COPARPA.

Em Jataí-GO, os assentamentos Rio Paraíso e Guadalupe produziram soja em parceria com o PNPB na safra 2010/2011. As famílias do assentamento Rio Claro iniciaram a parceria na safra de 2011/12. Já as famílias dos assentamentos Santa Rita, Terra e Liberdade não participam do Pro- 
grama. Em Perolândia, vinte e uma famílias do assentamento Três Pontes produziram em parceria com o PNPB na safra 2010/2011 e as famílias do assentamento Lagoa do Bonfim produzem soja, mas de forma individual e particular, não atreladas ao Programa.

As famílias pesquisadas dos assentamentos Guadalupe, Rio Claro e Três Pontes afirmaram que a participação no Programa se deu devido à necessidade de obterem mais renda da terra, que seria usada, principalmente, para pagamento de empréstimos já vencidos, inclusive com o PRONAF. Um outro motivo para a adesão ao Programa é a possibilidade de fertilização das terras por meio do cultivo da soja. De acordo com as famílias, se o Programa não produzir renda significativa, ao menos, a terra ficará um pouco mais fértil para um posterior cultivo de pastagem ou de alimentos devido aos tratos culturais realizados para o cultivo da soja. Desse modo, a intenção da produção camponesa da oleaginosa difere da intenção do Programa.

Para evitar interrupção na produção as empresas parceiras, como a Caramuru em Perolândia, estabelecem com as famílias camponesas contratos de produção da soja de, no mínimo, três anos, usando o argumento de que só a partir do terceiro ano do cultivo a terra rende a produtividade esperada.

O cultivo de soja nos municípios de Jataí e Perolândia, que é uma região com tradição na produção de grãos, coopta as famílias camponesas não apenas pela renda prometida, mas também pelo status que a produção de soja subjetivamente oferece, pois ser "plantador de soja" nessa região é sinônimo de riqueza. São distribuídos às famílias bonés, camisetas, canetas, além de outros souvenires com a "marca" do Programa transformando-as em divulgador deste e, por consequência, das empresas. Esses símbolos ainda servem ao propósito de conferir, com o envolvimento com a cadeia produtiva de grãos, o status de plantador de soja, o que diferencia "positivamente" esses produtores e assentamentos dos outros não envolvidos com a monocultura.

Para garantir a produção de soja pelo PNPB, a COPARPA “avaliza” o empréstimo às famílias, mesmo para aquelas que estão endividadas, fornecendo-lhes os insumos. Ainda, as famílias recebem assistência técnica e têm a garantia de que sua produção será comprada. A responsabilidade delas é entregar o montante contratado à empresa. Em função disso a cooperativa retém $5 \%$ do valor do contrato de produção de cada família.

Estas supostas vantagens que são disponibilizadas às famílias são formas de sujeição da terra ao agronegócio, pois em todo o processo de produção, desde a compra dos insumos até os descontos referentes ao que será pago às famílias, além delas estarem sujeitas ao mercado de commodities, não há liberdade na escolha dos insumos e da assistência técnica, na venda, no preço e nos descontos que as empresas podem fazer.

A relação entre as famílias, as empresas e as cooperativas parceiras no Programa não ocorre sem tensões. No caso pesquisado, as tensões se deram em função dos procedimentos burocráticos requeridos pelo Programa e da falta de conhecimento das leis que regem os contratos pela família. Algumas famílias passaram pelo constrangimento de assinar os contratos sem saber, ao certo, se as cláusulas estavam adequadas ao combinado. Como não receberam nenhuma cópia do contrato assinado, não têm como verificar com advogados, por exemplo, o que efetivamente se obrigavam.

Outros conflitos ocorrem pela exigência da aplicação no monocultivo de soja de tecnologias e de procedimentos que fogem à lógica camponesa. Um exemplo é que as famílias não sabiam como e quando usar adubo e venenos. Outro problema é que os insumos foram comprados em conjunto para depois serem distribuídos a todas as famílias envolvidas com o Programa, o que, por um lado, pode ser considerado mais vantajoso, pois diminui a perda de produtos. Mas, por outro, reduz a autonomia das famílias no manuseio e controle do seu material. As famílias não tinham como saber se estavam usando todo o volume de insumos que lhes era de direito, nem sabiam quem controlaria o uso e a distribuição do restante dos produtos, caso houvesse sobras. Isso gerou desconfiança entre as próprias famílias, uma vez que somente o grupo responsável pelo trabalho com o maquinário 
(tratores, plantadeiras etc.) é que pode ter acesso à gerência do gasto dos insumos. Fragilizam-se as relações entre as famílias, desagregando e criando conflitos internos à comunidade.

Da mesma forma, erros na medição da área de plantio da soja pelos técnicos da cooperativa, são constantes. Em três lotes do assentamento Três Pontes a área demarcada in locu para o plantio foi menor do que a área estabelecida no contrato. Assim, as famílias pagaram por insumos que não foram usados na sua lavoura, tendo prejuízo em relação ao custo da produção.

No caso do assentamento Três Pontes, as famílias conseguiram controlar parte do processo produtivo da soja em seus lotes. A empresa Caramuru quando estabelece parceira com famílias que não têm maquinários, as orienta a terceirizarem o serviço dos tratos culturais das lavouras e, nestes casos, ela faz o adiantamento dos recursos para o gasto dos maquinários, que depois serão descontados de acordo com o que foi gasto na produção de cada família. Nesse assentamento, as famílias formaram um grupo e adquiriram o maquinário com o valor do adiantamento. Esta foi não só uma forma encontrada para se ter maior controle sobre o processo produtivo, por se ter maquinário próprio, mas também pode criar outras possibilidades de cultivo, além da soja.

No que tange à assistência, as famílias fazem questão de que os técnicos visitem seus lotes e lavouras para repassar orientações, uma vez que não sabem lidar com a soja, que é uma cultura nova na sua prática produtiva. Mesmo sabendo que não podem interferir nos tratos da lavoura, que são ditados pelos manuais técnicos, sentem necessidade de aprender, de entender o processo produtivo e também por esse motivo recorrem aos técnicos.

Dessa forma, as famílias camponesas que aderem aos programas, tentam se adequar à sua racionalidade, mas, ao mesmo tempo, procuram brechas através das quais possam ter autonomia no uso da terra.

\section{CONSIDERAÇÕES FINAIS}

Os programas de produção e geração de renda para a agricultura familiar se mostram como uma oportunidade às famílias camponesas, especialmente as assentadas, de se colocarem no mercado, com garantia da comercialização da sua produção.

O Estado reconhece, por meio destas políticas, este grupo como digno de investimento público. No entanto, esses programas compõem o capitalismo no campo, que mantém as estruturas exploradoras do sistema. Cada família, individualmente, precisa verificar se, conforme sua estrutura social e econômica, os programas lhe convêm e quais estratégias podem usar para ajustá-los quando possível e necessário, para manterem, ao máximo, autonomia, ou alternativas, em relação ao mercado.

Logo, em relação aos programas aqui destacados, nota-se que há divergência entre as suas intenções e as das famílias camponesas e a forma como estas os tomam para si e os implantam. Os programas utilizam a lógica do sistema econômico, capitalista, buscando se impor às famílias, direcionando o trato com a terra e o modo de se produzir. Já as famílias querem se integrar aos programas de acordo com os tempos e usos da terra, na lógica própria do seu modo de vida.

É preciso, pois, repensar esses programas e quais são os benefícios que eles trazem para as famílias camponesas. Também é necessária a discussão sobre o uso do território para entender se as famílias camponesas não estão sendo virtualmente desterritorializadas.

Quando mediadores e agentes desses programas organizam suas ações, de acordo com os interesses do capitalismo, primeiramente admitem a existência da lógica camponesa da reprodução social, que está além das regras do mercado e que faz da terra uma terra de trabalho e de vida, para poder cooptá-la, subvertê-la, "capitalizá-la".

Assim, de qualquer modo, o território dos assentamentos está em constante conflito, pois é fruto de uma sociedade contraditória. No jogo de forças econômicas e políticas, quem mantém o controle da produção pode controlar o território. Por isso, os programas e suas bases teórico-metodológicas carecem sempre de análises que (re)orientem o uso do aparelho do Estado para a construção de um novo modelo de desenvolvimento, que leve em consideração o modo de vida camponês. 


\section{REFERÊNCIA BIBLIOGRÁFICA}

ABRAMOVAY, Ricardo. Paradigmas do capitalismo agrário em questão. Campinas: Editora Hucitec, ANPOCS, Editora da UNICAMP, 1992.

BRASIL. Lei no 11.326, de 24 de julho de 2006. Disponível em: http://www.mda.gov.br/portal/saf/. Acesso em 20 ago. 2010

DUVAL, Henrique Carmona; FERRANTE, Vera Lúcia Silveira Botta. Autoconsumo e políticas municipais: perspectivas de segurança alimentar e desenvolvimento. In: FERRANTE, Vera Lúcia Silveira Botta; WHITAKER, Dulce Consuelo Andreatta (Orgs). Reforma Agrária e Desenvolvimento: desafios e rumos da política de assentamentos rurais. Brasília: MDA; São Paulo: Uniara, 2008. p. 308-322

FELÍCIO, Munir Jorge. Os camponeses, os agricultores familiares: paradigmas em questão. Revista de Geografia. Londrina, v. 15, n. 1, p. 205-219, jan./jun. 2006. Disponível em: <www.uel.br/revistas/geografia/ v15n1digital/artigo12.pdf> Acesso em: 21 jul. 2010.

FERNANDES, Bernardo Mançano. Conflitualidade e desenvolvimento territorial: questão agrária. In: BUAINAIN, A. M. (org.). Luta pela terra, reforma agrária e gestão de conflitos no Brasil. Campinas: Unicamp, 2008. p. 173-230

FERNANDES, Bernardo Mançano. Questão Agrária, Pesquisa e MST. São Paulo: Cortez, 2001. Coleção Questões de Nossa Época (v. 92)

FLEXOR, Georges. A economia política da construção institucional do mercado de biodiesel no Brasil. In: BONNAL, Philippe; LEITE, Sérgio Pereira (orgs). Análise Comparada de Políticas Agrícolas. Rio de Janeiro: Mauad X, 2011. p. 363-387

GRISA, Cátia; WESZ JR, Valdemar. Políticas Públicas para a Agricultura Familiar: entre avanços e desafios. Observatório de Políticas Públicas para a Agricultura. Rio de Janeiro: CPDA, n.33, maio 2010. Disponível em http://oppa.net.br/artigos/portugues/artigo_OPPA_br_033-05_2010-catia_junior.pdf.pdf Acesso em: 15 jul. 2011

MARQUES, Marta Inês Medeiros. Terra e Modernidade em Assentamentos de Reforma Agrária. In: WOORTMANN, Ellen F. (Org). Significados da Terra. Brasília: Editora da Universidade de Brasília, 2004. p. 255-286

MAZZETTO-SILVA, Carlos Eduardo. O cerrado em disputa: apropriação global e resistências locais. Brasília: Confea, 2006.

MINISTÉRIO DO DESENVOLVIMENTO AGRÁRIO, 2010. Disponível em: <http://www.mda.gov.br/ potal/saf/>. Acesso em 25 jul. 2010.

NEVES, Delma Pessanha. Assentamento rural: confluência de formas de inserção social. Estudos, Sociedade e Agricultura. Revista Semestral de Ciências Sociais Aplicadas ao Estudo do Mundo Rural. Rio de Janeiro: CPDA, n.13, out. 1999: 5-28. Disponível em http://bibliotecavirtual.clacso.org.ar/ar/libros/brasil/ cpda/estudos/treze/delma13.htm. Acesso em 30 out. 2010

OLIVEIRA, Ariovaldo Umbelino. Modo de Produção Capitalista, Agricultura e Reforma Agrária. São Paulo: Labur Edições, 2007. 184 p.

PAULINO, Eliane Tomiasi. Polticas Territoriais e Questão Agrária: da teoria à intervenção. In: SAQUET, Marcos Aurelio; SANTOS, Roseli Alves (Orgs). Geografia Agrária, Território e Desenvolvimento. São Paulo: Expressão Popular, 2010. p. 107-129.

PNPB - PROGRAMA NACIONAL DE PRODUÇÃO E USO DE BIODIESEL, 2011. Disponível em http:// www.biodiesel.gov.br/. Acessado em janeiro de 2011.

REPÓRTER BRASIL. Os impactos da soja na safra 2009/10. Disponível em: $<$ http://www.reporterbrasil. com.br/estudo_soja_cma_reporter_brasil_2010.pdf>. Acesso em: 18 out. 2010.

Trabalho enviado em janeiro de 2013

Trabalho aceito em fevereiro de 2013 